\title{
Comparison of European Standard Patch Test Results of 330 Patients from an Occupational Diseases Hospital
}

\author{
Özge Gündüz, ${ }^{1}$ Aslı Aytekin, ${ }^{2}$ Engin Tutkun, ${ }^{3}$ and Hınç Yılmaz ${ }^{3}$ \\ ${ }^{1}$ Ufuk University Faculty of Medicine, Department of Dermatology, Ankara, Turkey \\ ${ }^{2}$ Department of Dermatology, Ankara Occupational Diseases Hospital, Ankara, Turkey \\ ${ }^{3}$ Department of Occupational Diseases, Ankara Occupational Diseases Hospital, Ankara, Turkey \\ Correspondence should be addressed to Özge Gündüz; drozgegunduz@yahoo.com
}

Received 15 July 2016; Accepted 8 September 2016

Academic Editor: Giuseppe Stinco

Copyright ( 2016 Özge Gündüz et al. This is an open access article distributed under the Creative Commons Attribution License, which permits unrestricted use, distribution, and reproduction in any medium, provided the original work is properly cited.

\begin{abstract}
Background and Aim. Contact dermatitis (CD) is the most prevalent occupational skin disease with a significant impact on quality of life. Patch testing is used for the identification of responsible allergens which may improve protective and preventive measures in the workplace. Herein, we aim to identify the demographic characteristics and occupation of patients with early diagnosis of occupational CD and compare patch test results. Materials and Methods. The study included 330 patients referred to our clinic between April 2009 and April 2011 and who were patch-tested with 28-allergen European Standard Test. Results. 126 (38\%) patients were female and $204(62 \%)$ were male with a mean age of $36.12( \pm 13.13)$ years. Positive allergic reactions were observed in $182(55 \%)$ patients. Nickel sulphate (41/126) and potassium dichromate (39/204) were significantly the most common allergens in women and men, respectively $(P<0.005)$. Additionally, the most common occupation in women was household activities $(83 / 126)$ and in men was manufacturing (80/204). Conclusion. The allergens to which people become sensitized differ according to their working environment and occupation. Classification of occupations is important for identification of sensitization risks and monitoring of changes in allergen distribution of different occupations.
\end{abstract}

\section{Introduction}

Contact dermatitis (CD) is the most prevalent occupational skin disease, comprising $90 \%$ of reported job-related cases [1]. Occupational CD (OCD) may necessitate sick leave and has been shown to have a significant impact on quality of life [2]. Eighty percent of all OCD cases are attributed to irritant CD and the remaining to allergic $\mathrm{CD}[3,4]$. Contrary to irritant $\mathrm{CD}$, allergic $\mathrm{CD}$ is mediated by a delayed-type hypersensitivity reaction which can be shown on patch testing. Patch testing is an important diagnostic tool for the identification of allergens responsible for dermatitis and the differentiation between allergic and irritant $\mathrm{CD}$. However, in reality, the causes of allergic OCD are often multifactorial in origin and various irritating factors in the working environment may contribute to the penetration of allergens into the skin.

In our country, The Occupational Diseases Hospital specializes in making medicolegal decisions regarding occupational diseases and can be attended by all workers throughout the country. Patients are evaluated in the hospital's Occupational Diseases Policlinic by physicians with expertise in occupational diseases. Additionally, local patients may also visit the Dermatology Outpatient Clinic.

In this study, we aim to identify the demographic characteristics and occupation of patients who had attended the Dermatology Policlinic of an Occupational Diseases Hospital with early diagnosis of OCD and compare the patch test results with these variables.

\section{Materials and Methods}

This retrospective descriptive study included 330 patients who visited or were referred to the Dermatology Policlinic between April 2009 and April 2011. After referral to the Dermatology Clinic, full clinical and thorough occupational history was taken and physical examination and subsequent investigation using patch testing were made for the diagnosis 
TABLE 1: Comparison of patch test results of men and women.

\begin{tabular}{|c|c|c|c|}
\hline & Women $(n=126)$ & $\operatorname{Men}(n=204)$ & $P$ \\
\hline Age (years) & 33,31 & 37,12 & 0.372 \\
\hline Positive reaction & 78 & 104 & 0.085 \\
\hline \multicolumn{4}{|l|}{ Allergens } \\
\hline Potassium dichromate & 9 & 39 & 0.005 \\
\hline Rubber accelerator & 1 & 19 & 0.001 \\
\hline Cobalt(II) chloride & 24 & 19 & 0.007 \\
\hline Nickel sulphate & 41 & 22 & $<0.001$ \\
\hline Fragrance mix I and II & 19 & 12 & 0.037 \\
\hline Balsam of Peru & 13 & 8 & 0.034 \\
\hline \multicolumn{4}{|l|}{ Occupations } \\
\hline & $\begin{array}{c}\text { Household } \\
\text { activities } \\
n=83(65.8 \%)\end{array}$ & $\begin{array}{c}\text { Manufacturing } \\
n=80(39.2 \%)\end{array}$ & \\
\hline
\end{tabular}

Rubber accelerator: thiuram mix, mercapto mix, and mercaptobenzothiazole.

of occupational contact dermatitis. Patch tests were performed on all patients according to the European Standard Series (ESS) of 28 allergens using IQ Chambers (Chemotechnique Diagnostics, Sweden). Patients were not tested with additional allergens. In line with the clinic's protocol, patch tests were applied to patients' back for a duration of 48 hours. Readings were made at the 48th, 72nd, and 96th hours in accordance with International Contact Dermatitis Research Group (ICDRG) guidelines. An erythematous reaction limited to the application site, which usually fades within 96 hours, and follicular pustules were considered as irritant reactions. Patients were tested one week after discontinuation of antihistamines and topical corticosteroid therapy and at least four weeks after cessation of immunosuppressive agents. Pregnant and lactating women were not included.

The patients were questioned about their job, working environment, protective measures, and hobbies or sparetime activities. The final diagnosis was made after clinical examination, patch testing, and assessment of clinical relevance which were evaluated based on questioning the patient regarding the relation between the work process and exposure of skin to allergens; medical files and material safety data sheets were collected from occupational physician. Patient files were retrospectively reviewed and demographic properties recorded. This study was approved by local ethics committee (22/02/2012-20).

Predictive Analytics Software (PASW) version 18.0 for Windows (SPSS Inc., Chicago, IL, USA) was used for all analyses. The single-sample Kolmogorov-Smirnov test was performed to determine data distribution and continuous variables were compared with Students' $t$-test and categorical variables were compared with the Chi-square test. A significance level of 0.05 was used for all analysis.

\section{Results}

Of the 330 patients, 126 (38\%) were female and 204 (62\%) were male. Mean age was $36.12( \pm 13.13)$ years. There was a history of atopy in $99(30 \%)$ patients. Patients' most common complaint was pruritus $(23 \%)$. The most frequently affected areas were the hands alone (53\%), the face and neck (14\%), and the hands and feet combined (8\%).

One $(22 \%)$ or more than one $(33 \%)$ positive allergic reactions were observed in 182 (55\%) patients. The most common allergens causing positive reactions were nickel sulphate $(n=63,19 \%)$, potassium dichromate $(n=48$, $14.5 \%)$, and cobalt chloride $(n=43,13 \%)$. The least common allergens were wool alcohols $(n=1), \mathrm{N}$-isopropyl-N-phenyl4-phenylenediamine ( $n=2)$, and Quaternium $(n=2)$. Among all the tested patients, positive reactions were noted to all allergens in the ESS. Nickel sulphate and potassium dichromate were significantly the most common allergens in women and men, respectively (Table 1). There was no significant difference in multiple allergen positivity between women $(37 \%, n=47)$ and men $(27.9 \%, n=57)$ (Chi-square test, $P=0.13)$.

The final diagnosis after clinical examination, patch testing, and assessment of clinical relevance are presented in Figure 1. The distribution of patients according to Statistical Classification of Economic Activities in the European Community (NACE) codes is shown in Table 2.

\section{Discussion}

CD mainly affects the exposed areas of the body such as the hands, face, and neck. Similarly, these areas were the most frequently affected sites in our study. Although the list of top allergens varies between countries, nickel sulphate is the most commonly reported sensitizer in most parts of the world (Table 3). Sensitization rates differ from one country to another, ranging from $13.8 \%$ to $24.4 \%$ [5-12]. In previous studies conducted in Turkey, the frequency of positive patch test reactions were reported as $32.3 \%$ and $51.6 \%[13,14]$. Although in the present study our population is relatively small, one or more positive allergic reactions were observed in $55 \%$ of patients, which might be due to 
76 not work-related

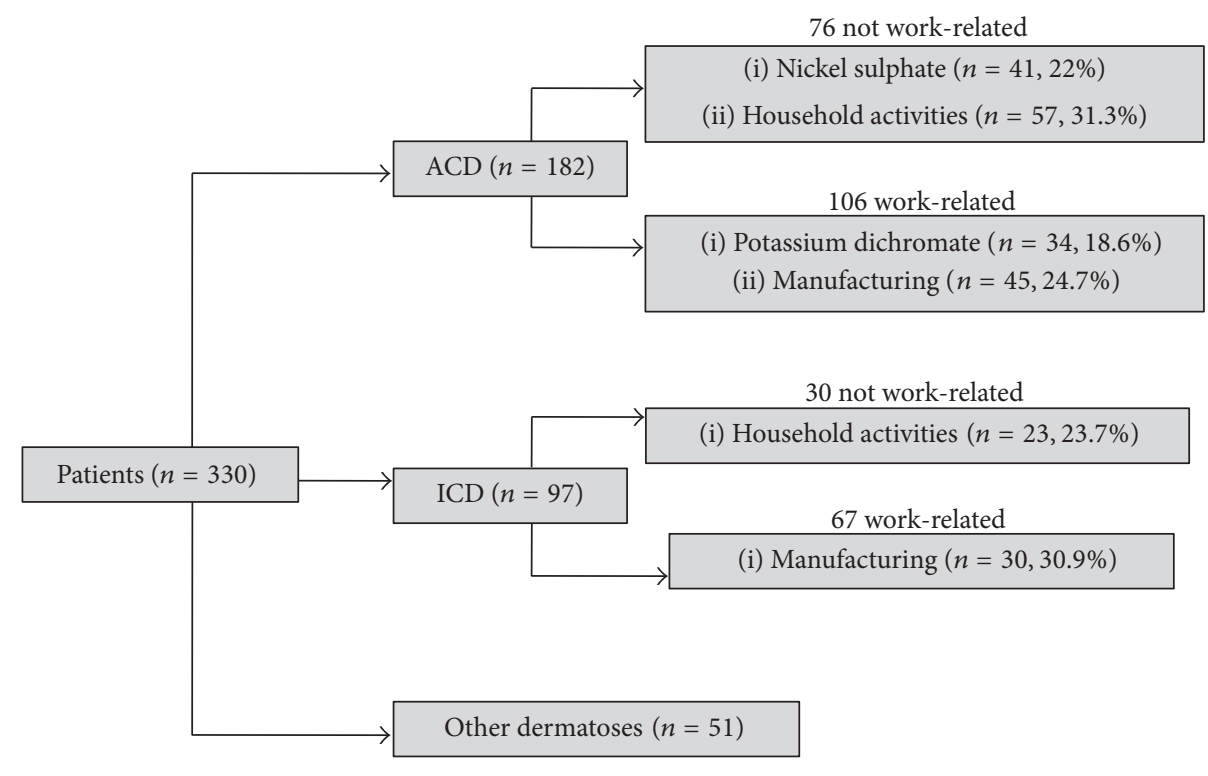

FIGURE 1: Final diagnosis after determination of clinical relevance.

the fact that this study was conducted in an occupational diseases specified hospital where the study population was composed of patients who might be exposed to multiple different allergens in the work environment. Similar to the studies of Akasya-Hillenbrand and Özkaya-Bayazit and Akyol et al., which reported nickel sensitivity of $17.6 \%$ and $19.1 \%$, respectively, the most common allergens causing positive reactions in our study were nickel sulphate (19\%), potassium dichromate (14.5\%), and cobalt chloride (13\%) $[13,14]$. Although, potassium dichromate and cobalt chloride sensitivity was similar in our study (14.5\% and $13 \%$, resp.) to that of Akasya-Hillenbrand and Özkaya-Bayazit (11.8\% and $8.5 \%$, resp.), our results were more frequent than those of Akyol et al. (4.6\% and 5.3\%, resp.) [13, 14]. The reason for this difference might be due to location: Akasya-Hillenbrand and Özkaya-Bayazit's study was conducted in the highly industrialized city of Istanbul whereas Akyol et al.s study was held in Ankara, a governmental city [13, 14]. This also favors the fact that the variation in the occupations of study populations leads to various allergen exposures in the work environment and the difference in patch test results. In addition, the fact that nickel and/or chromate sensitivity was accompanied by cobalt sensitivity was expected.

In terms of allergic reaction frequency, no difference was found between men (51\%) and women (62\%) $(P=0.085)$. However, the most common allergens in which women and men became sensitized to are significantly different (Table 1). Similarly, nickel allergy is reported to be the most common allergen among young women, and ear piercing was a common risk factor for developing nickel allergy while CD caused by chromate sensitivity is reported to be more common in men and is thought to be caused by occupational exposure to soluble compounds in cement or leather $[15,16]$. Potassium dichromate is found in cement, textile inks, paints, varnishes, and leather processes, whereas thiuram mix, mercapto mix, and mercaptobenzothiazole are rubber accelerators which are components of both natural and synthetic rubber and are also found in gloves [17]. Additionally, female patients were significantly more frequently sensitized by fragrance mix $(n=19)$ and balsam of Peru $(n=13)$; both are found in perfumes and cross react with each other. The difference in sensitization between men and women might be due to the fact that most common occupations in women and men were household activities (83/126) and manufacturing (80/204), respectively. Therefore, men might be exposed to multiple and various allergens with inadequate protective measures in their working environment. Additionally, significant rubber accelerator allergy in working men might be also due to the use of protective gear (i.e., gloves and rubber boots) during working hours. Unfortunately, sensitivity to chromium and nickel is related to a worse prognosis of occupational ACD as these allergens are ubiquitous in the environment and are therefore difficult to avoid [3].

In our study of 330 patients, $52 \%$ were diagnosed as having OCD. Allergic OCD affected 106 (61.3\%) patients, and irritant OCD was found in 67 (38.7\%). Although our study was comprised of a limited number of patients, it is the first study focused on OCD from an Occupational Diseases Hospital; therefore it represents a wide range of patients with different occupations throughout the country.

NACE is used for the classification of economic activities in the European Union since 1970. Classification of occupations according to NACE enable us to enlighten the distribution of risk groups. In NACE classification, housewives and retirees $(n=100)$ comprised the most common occupational group, followed by manufacturing $(n=85)$. Those working in the manufacturing area also constituted the majority of those diagnosed with occupational ACD or ICD (Figure 1). Potassium dichromate was the most common allergen in those working in the sectors of manufacturing (10/45) and construction (11/17) whereas nickel sulphate was most common in patients in the household (33/59) and education 
TABLE 2: Comparison of occupations according to NACE codes and patch test positivity.

\begin{tabular}{|c|c|c|c|}
\hline Occupations & \# of patients & \# of positive results & Most common allergens $(n)$ \\
\hline Agriculture, forestry, and fishing & 1 & 1 & \\
\hline Mining, quarrying & 4 & 3 & \\
\hline Manufacturing & 85 & 45 & Potassium dichromate (10) \\
\hline \multicolumn{4}{|l|}{$\begin{array}{l}\text { Electricity, gas, steam and air } \\
\text { conditioning supply }\end{array}$} \\
\hline \multicolumn{4}{|l|}{$\begin{array}{l}\text { Water supply, sewerage, waste } \\
\text { management, and remediation activities }\end{array}$} \\
\hline Construction & 29 & 17 & Potassium dichromate (11) \\
\hline $\begin{array}{l}\text { Wholesale and retail trade, repair of } \\
\text { motor vehicles and motorcycles }\end{array}$ & 27 & 11 & Cobalt(II) chloride (5) \\
\hline Transportation and storage & 5 & 3 & \\
\hline $\begin{array}{l}\text { Accommodation and food service } \\
\text { activities }\end{array}$ & 3 & 1 & \\
\hline \multicolumn{4}{|l|}{ Information and communication } \\
\hline \multicolumn{4}{|l|}{ Financial and insurance activities } \\
\hline \multicolumn{4}{|l|}{ Real estate activities } \\
\hline $\begin{array}{l}\text { Professional, scientific, and technical } \\
\text { activities }\end{array}$ & 9 & 6 & \\
\hline $\begin{array}{l}\text { Public administration and defence, } \\
\text { compulsory social security }\end{array}$ & 4 & 2 & \\
\hline Education & 34 & 17 & Nickel sulphate (9) \\
\hline Human health and social work activities & 9 & 6 & \\
\hline Arts, entertainment, and recreation & 1 & 0 & \\
\hline Other service activities & 19 & 11 & Potassium dichromate (4) \\
\hline $\begin{array}{l}\text { Activities of households as employers, } \\
\text { undifferentiated goods- and services- } \\
\text { producing activities of households for } \\
\text { own use }\end{array}$ & 100 & 59 & Nickel sulphate (33) \\
\hline \multicolumn{4}{|l|}{$\begin{array}{l}\text { Activities of extraterritorial organisations } \\
\text { and bodies }\end{array}$} \\
\hline Total & 330 & 182 & \\
\hline
\end{tabular}

(9/17) groups. The major sources of chromate exposure are construction materials (cement, drywall), leather, and metalworking occupations (welding, plating, and dyeing) [18]. Also the working environment can be easily contaminated by cement dust or chromate containing solutions, which makes the prognosis for the chromate-sensitized patient poor [19]. Therefore, those patients who were diagnosed as occupational ACD were suggested a change of job. Household and education groups were mainly composed of women who were most frequently sensitized by nickel. Additionally, wet work, such as in household activities, causes skin barrier damage and increases the risk of developing hand eczema for individuals with nickel allergy [20].

The main limitation of our study was the relatively small population. Additionally, two different dermatologists performed readings and interpretations of patch tests and did not check each other's work. The fact that patients were evaluated by different clinicians may be considered as another limitation of this study.
In conclusion, this study shows that allergens to which people are sensitive differ according to their working environment and type of occupation. We would like to emphasize that classification of occupations using an international standard such as the NACE Coding is important for the identification of sensitization risks of different occupations, the comparison of study results, and the monitoring of changes in allergen distribution of different occupations.

\section{Disclosure}

This study was conducted in Ankara Occupational Diseases Hospital, Ankara, Turkey.

\section{Competing Interests}

All authors gave their approval on the manuscript and its content, and there is no financial support or conflict of interests. 
TABLE 3: Most common allergens in previous studies.

\begin{tabular}{|c|c|c|c|c|c|c|}
\hline & Country & $\#$ of pt & $\begin{array}{l}\text { \# of positive } \\
\text { reactions (\%) }\end{array}$ & \multicolumn{3}{|c|}{ Most common 3 allergens (\%) } \\
\hline Our results & Turkey & 330 & $\begin{array}{c}182 \\
(55 \%)\end{array}$ & $\begin{array}{c}\text { Nickel sulphate } \\
(19 \%)\end{array}$ & $\begin{array}{l}\text { Potassium } \\
\text { dichromate } \\
(14.5 \%)\end{array}$ & $\begin{array}{c}\text { Cobalt chloride } \\
(13 \%)\end{array}$ \\
\hline $\begin{array}{l}\text { Akasya-Hillenbrand } \\
\text { and Ozkaya-Bayazit } \\
{[13]}\end{array}$ & Turkey & 542 & $\begin{array}{c}280 \\
(51.6 \%)\end{array}$ & $\begin{array}{l}\text { Nickel sulphate } \\
\quad(19.1 \%)\end{array}$ & $\begin{array}{l}\text { Potassium } \\
\text { dichromate } \\
(11.8 \%)\end{array}$ & $\begin{array}{l}\text { Palladium chloride } \\
\qquad(9.4 \%)\end{array}$ \\
\hline Akyol et al. [14] & Turkey & 1038 & $\begin{array}{c}336 \\
(32.3 \%)\end{array}$ & $\begin{array}{l}\text { Nickel sulphate } \\
\quad(17.6 \%)\end{array}$ & $\begin{array}{c}\text { Cobalt chloride } \\
(5.3 \%)\end{array}$ & $\begin{array}{c}\text { Potassium } \\
\text { dichromate }(4.6 \%)\end{array}$ \\
\hline Beliauskiene et al. [5] & Lithuania & 816 & $\begin{array}{c}384 \\
(47.4 \%)\end{array}$ & $\begin{array}{l}\text { Nickel sulphate } \\
\quad(16.4 \%)\end{array}$ & $\begin{array}{c}\text { Balsam of Peru } \\
\quad(8.6 \%)\end{array}$ & $\begin{array}{c}p- \\
\text { Phenylenediamine } \\
(5.8 \%)\end{array}$ \\
\hline Bilcha et al. [6] & Ethiopia & 514 & $\begin{array}{c}271 \\
(52.7 \%)\end{array}$ & $\begin{array}{c}\text { Nickel sulphate } \\
(17.7 \%)\end{array}$ & $\begin{array}{c}\text { Fragrance mix I } \\
\qquad(14.8 \%)\end{array}$ & $\begin{array}{c}\text { Cobalt chloride } \\
(8.0 \%)\end{array}$ \\
\hline Lam et al. [7] & Hong Kong & 2585 & $\begin{array}{c}1415 \\
(54.7 \%)\end{array}$ & $\begin{array}{c}\text { Nickel sulphate } \\
\quad(24.4 \%)\end{array}$ & $\begin{array}{c}\text { Fragrance mix } \\
\quad(13.7 \%)\end{array}$ & $\begin{array}{c}\text { Cobalt chloride } \\
(8.7 \%)\end{array}$ \\
\hline Lazarov [8] & Israel & 2156 & $\begin{array}{c}937 \\
(43.5 \%)\end{array}$ & $\begin{array}{l}\text { Nickel sulphate } \\
\quad(13.9 \%)\end{array}$ & $\begin{array}{c}\text { Fragrance mix } \\
(7.1 \%)\end{array}$ & $\begin{array}{c}\text { Potassium } \\
\text { dichromate }(3.8 \%)\end{array}$ \\
\hline Wetter et al. [9] & USA & 1324 & $\begin{array}{c}917 \\
(69.3 \%)\end{array}$ & $\begin{array}{l}\text { Nickel sulphate } \\
\quad(14.1 \%)\end{array}$ & $\begin{array}{c}\text { Balsam of Peru } \\
\quad(11.3 \%)\end{array}$ & $\begin{array}{c}\text { Neomycin sulphate } \\
(11.2 \%)\end{array}$ \\
\hline Machovcova et al. [10] & Czech Republic & 12058 & $\begin{array}{c}7661 \\
(63.5 \%)\end{array}$ & $\begin{array}{l}\text { Nickel sulphate } \\
\quad(13.7 \%)\end{array}$ & $\begin{array}{l}\text { Balsam of Peru } \\
\quad(7.28 \%)\end{array}$ & $\begin{array}{c}\text { Fragrance mix } \\
(5.7 \%)\end{array}$ \\
\hline Lestringant et al. [11] & United Arab Emirates & 373 & $\begin{array}{c}224 \\
(60 \%)\end{array}$ & $\begin{array}{c}\text { Nickel sulphate } \\
(15 \%)\end{array}$ & $\begin{array}{c}\text { Fragrance mix } \\
\quad(8.0 \%)\end{array}$ & $\begin{array}{l}\text { PTBP } \\
(7.5 \%)\end{array}$ \\
\hline
\end{tabular}

\#: number; pt: patients; USA: United States of America; PTBP: p-tert-butylphenol formaldehyde resin.

\section{Acknowledgments}

The authors gratefully acknowledge the manuscript review of Professor Dr. Meltem Önder and statistical analysis of Assistant Professor Dr. Aslihan Alhan.

\section{References}

[1] W. N. Rom and S. B. Markowitz, Environmental and Occupational Medicine, Lippincott, Williams and Wilkins, 4th edition, 2007.

[2] C. V. Hutchings, K. W. Shum, and D. J. Gawkrodger, "Occupational contact dermatitis has an appreciable impact on quality of life," Contact Dermatitis, vol. 45, no. 1, pp. 17-20, 2001.

[3] D. V. Belsito, "Occupational contact dermatitis: etiology, prevalence, and resultant impairment/disability," Journal of the American Academy of Dermatology, vol. 53, no. 2, pp. 303-313, 2005.

[4] M. Antezana and F. Parker, "Occupational contact dermatitis," Immunology and Allergy Clinics of North America, vol. 23, no. 2, pp. 269-290, 2003.

[5] A. Beliauskiene, S. Valiukeviciene, W. Uter, and A. Schnuch, "The European baseline series in Lithuania: results of patch testing in consecutive adult patients," Journal of the European Academy of Dermatology and Venereology, vol. 25, no. 1, pp. 5963, 2011.

[6] K. D. Bilcha, A. Ayele, D. Shibeshi, and C. Lovell, "Patch testing and contact allergens in Ethiopia-results of 514 contact dermatitis patients using the European baseline series," Contact Dermatitis, vol. 63, no. 3, pp. 140-145, 2010.
[7] W. S. Lam, L. Y. Chan, S. C. K. Ho, L. Y. Chong, W. H. So, and T. W. Wong, "A retrospective study of 2585 patients patch tested with the European standard series in Hong Kong (1995-99)," International Journal of Dermatology, vol. 47, no. 2, pp. 128-133, 2008.

[8] A. Lazarov, "European Standard Series patch test results from a contact dermatitis clinic in Israel during the 7-year period from 1998 to 2004," Contact Dermatitis, vol. 55, no. 2, pp. 73-76, 2006.

[9] D. A. Wetter, M. D. P. Davis, J. A. Yiannias et al., "Patch test results from the Mayo Clinic contact dermatitis group, 19982000," Journal of the American Academy of Dermatology, vol. 53, no. 3, pp. 416-421, 2005.

[10] A. Machovcova, E. Dastychova, D. Kostalova et al., "Common contact sensitizers in the Czech Republic. Patch test results in 12,058 patients with suspected contact dermatitis," Contact Dermatitis, vol. 53, no. 3, pp. 162-166, 2005.

[11] G. G. Lestringant, A. Bener, M. Sawaya, I. H. Galadari, and P. M. Frossard, "Allergic contact dermatitis in the United Arab Emirates," International Journal of Dermatology, vol. 38, no. 3, pp. 181-186, 1999.

[12] W. Uter, C. Rämsch, W. Aberer et al., "The European baseline series in 10 European countries, 2005/2006-results of the European Surveillance System on Contact Allergies (ESSCA), Contact Dermatitis, vol. 61, no. 1, pp. 31-38, 2009.

[13] E. Akasya-Hillenbrand and E. Özkaya-Bayazit, "Patch test results in 542 patients with suspected contact dermatitis in Turkey," Contact Dermatitis, vol. 46, no. 1, pp. 17-23, 2002.

[14] A. Akyol, A. Boyvat, Y. Peksarı, and E. Gürgey, "Contact sensitivity to standard series allergens in 1038 patients with 
contact dermatitis in Turkey," Contact Dermatitis, vol. 52, no. 6, pp. 333-337, 2005.

[15] F. Rui, M. Bovenzi, A. Prodi et al., "Nickel, cobalt and chromate sensitization and occupation," Contact Dermatitis, vol. 62, no. 4, pp. 225-231, 2010.

[16] N. H. Nielsen, A. Linneberg, T. Menné et al., "Incidence of allergic contact sensitization in Danish adults between 1990 and 1998; the Copenhagen Allergy Study, Denmark," British Journal of Dermatology, vol. 147, no. 3, pp. 487-492, 2002.

[17] A. Boyvat and A. Akyol, "Contact sensitizers included in the standard patch test series," Turkiye Klinikleri J Allergy-Asthma, vol. 2, pp. 156-167, 2000.

[18] A. A. Fisher, "Chromates: prime causes of industrial allergic contact dermatitis ," Cutis, vol. 32, article 24, 1983.

[19] R. Breit and R. B. M. Tuerk, "The medical and social fate of the dichromate allergic patient," British Journal of Dermatology, vol. 94, no. 3, pp. 349-350, 1976.

[20] B. Meding, "Differences between the sexes with regard to workrelated skin disease," Contact Dermatitis, vol. 43, no. 2, pp. 6571, 2000. 


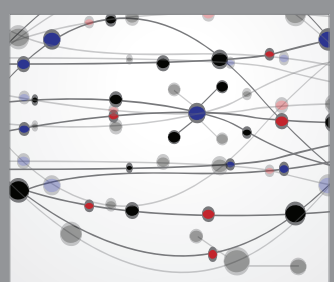

The Scientific World Journal
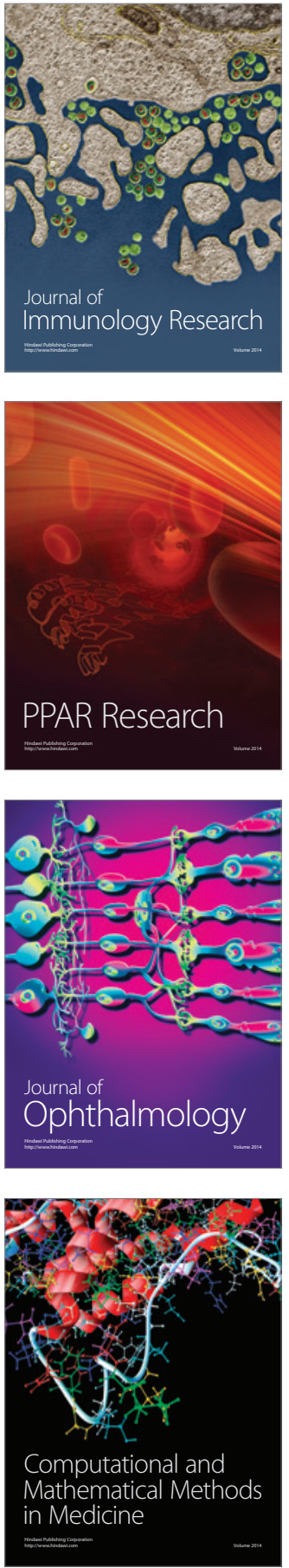

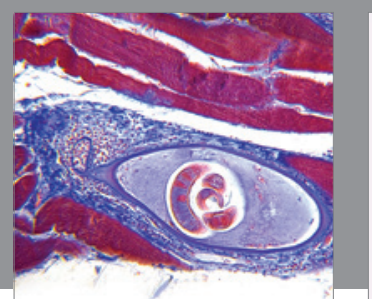

Gastroenterology Research and Practice

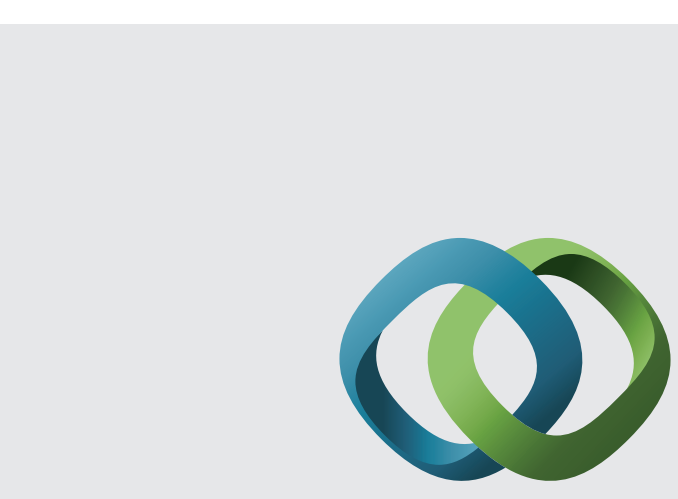

\section{Hindawi}

Submit your manuscripts at

http://www.hindawi.com
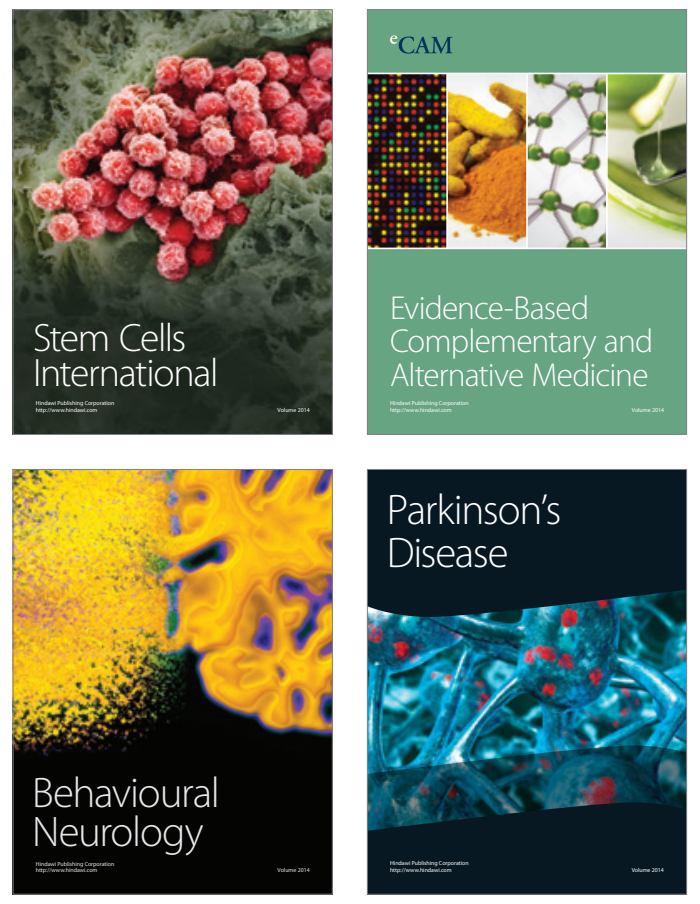
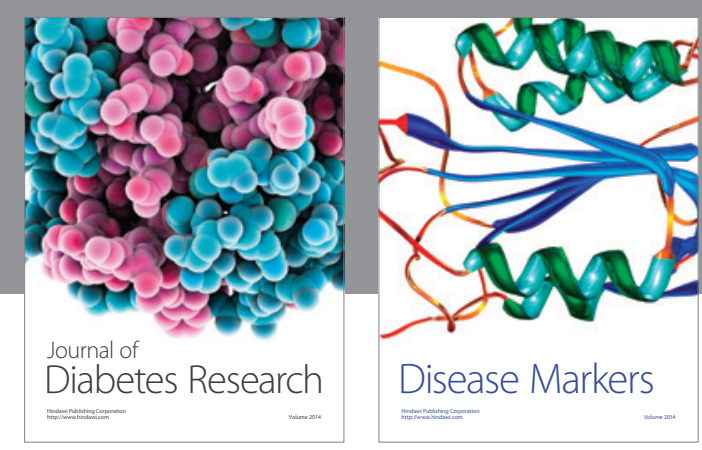

Disease Markers
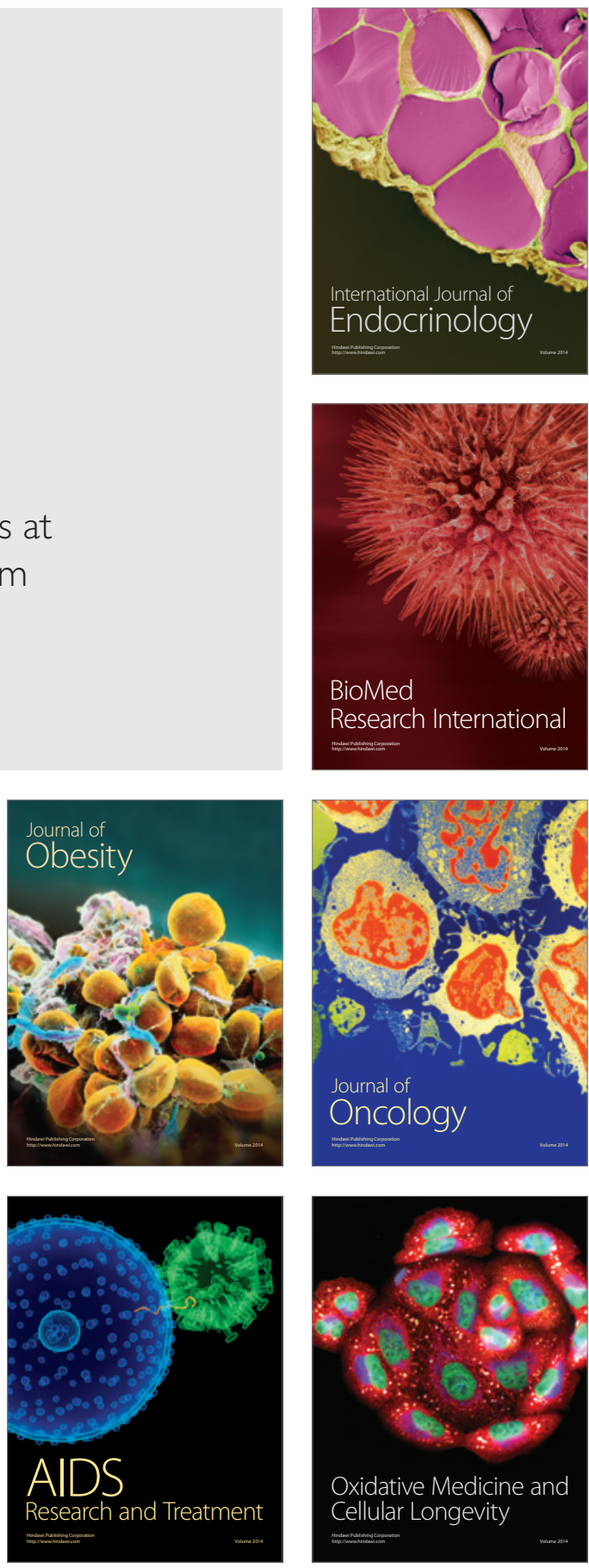